\title{
A Needs analysis of the Post-graduate Students' Academic English in the Faculty of Arts, Cairo University $(*)$
}

\author{
Supervised by: \\ Prof. Ola M. Hafez \\ Faculty of Arts, Cairo University
}

\section{Heba Ismail Bakry Aly \\ Assistant Lecturer - Department of English Language and Literature, Cairo University}

\begin{abstract}
This needs assessment study falls in the mixed research paradigm as it combines both qualitative and quantitative methodologies by means of interviews and surveys. The objective of the study is to have a closer look at the students' current knowledge and expectations of studying English for purposes relevant to their academic interests. The needs were analyzed, from the perspective of the English and specialized teachers and from the perspective of the students themselves. Discovery interviews were conducted first with teachers from the English Department who taught postgraduate courses in departments other than English, to study their opinion from a language-specialized perspective. Following these interviews, a questionnaire was filled by 16 teachers and professors from the other departments to survey their opinion from a more subject-specialized point of view. The same procedures were repeated with a convenient sample of MA and $\mathrm{PhD}$ students. Interviews were conducted with $10 \mathrm{MA}$ and $\mathrm{PhD}$ students, followed by a questionnaire filled by a convenient sample of $100 \mathrm{MA}$ and $\mathrm{PhD}$ students in the Faculty of Arts. The teachers' data showed that there is a consensus that the current undergraduate EAP syllabi are not sufficient and does not prepare the postgraduate students for an advanced EAP writing course. As for the students' data, they showed that the reading skill is more important than the writing skill. Finally, this needs assessment offered a number of recommendations that should help improve the English research writing skills of the postgraduates of the Faculty of Arts, Cairo University.
\end{abstract}

(*) A Needs analysis of the Post-graduate Students' Academic English in the Faculty of Arts, Cairo University, Vol. 10, Issue No.1, Jan. 2021, pp.47-76. 


\section{Keywords:}

Needs Assessment, English for Academic Purposes, Postgraduates, Nonnative speakers of English

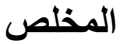

إن إتقان اللغات الأجنبية وأساليبها البلاغية يساعد على انتشار الإنتاج البحثي ليخدم

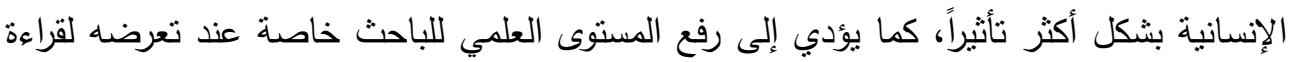
الإصدارات البحثية الدولية وتحليلها ومناقشتها، دون التوقف عند قراءة الإصدارات المحلية فقط.

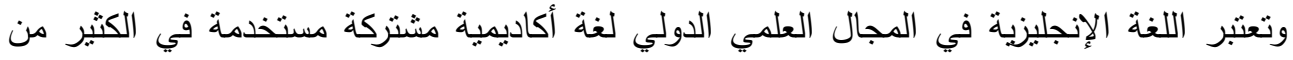

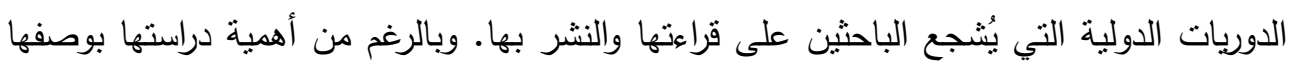

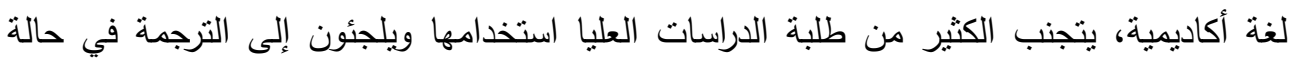

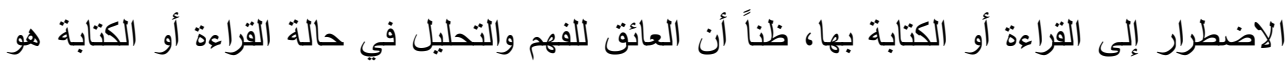

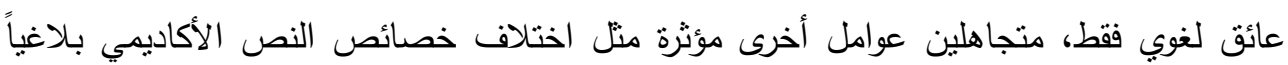

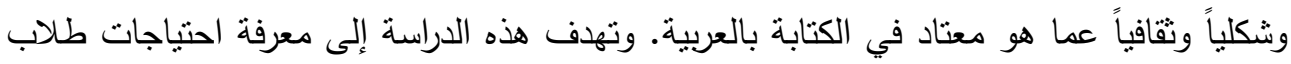

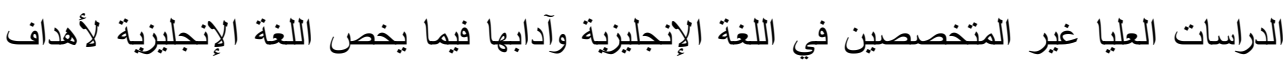

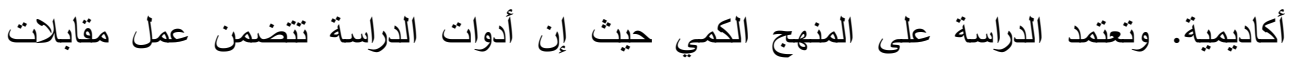

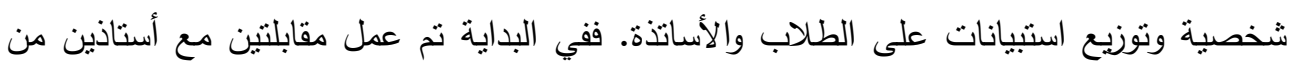
أساتذة اللغة الإنجليزية الذين قاموا بالفعل بالتدريس في الأقسام الأخرى، كما تم توزيع 17 استبانة

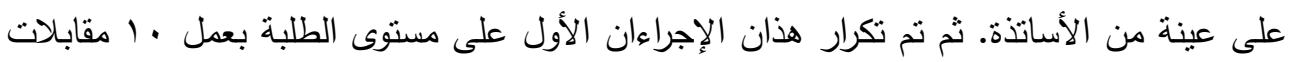

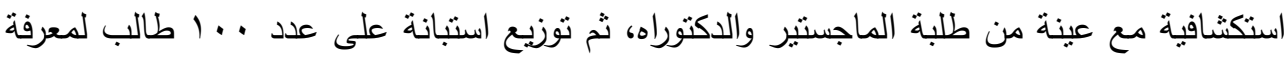

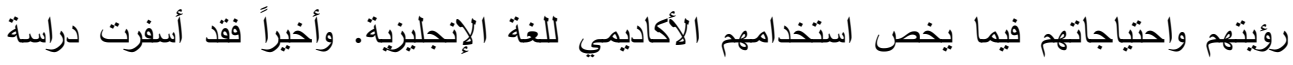

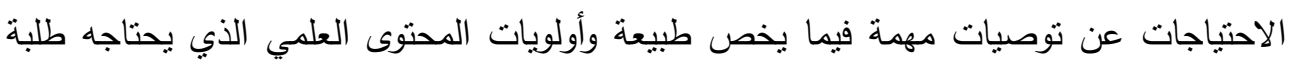
الدراسات العليا.

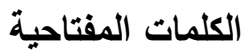

دراسة الاحتباجات، اللغة الإنجليزية لأهداف أكاديمية، طلبة الدراسات العليا، اللغة الإنجليزية

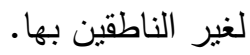




\section{Introduction}

Needs Assessments (NA) are the tools applied to determine deficiencies in the workplace. They help decision makers in assessing the status quo to find out the lacks, needs and wants of the stakeholders. Applying needs assessment training is a common procedure in many fields, such as schools, businesses, institutions, and health organizations, and is normally administered by an external consultant or facilitator (Altschuld, \& Eastmond, 2010). However, most of the assessment reports are occluded and not published, which leads organizations with similar objectives and needs to reinvent the wheel every time they apply an NA.

Although needs surveys are very significant for syllabus design because they present the decision maker with statistics to work with (Ostler 1980), it must be acknowledged that needs are never universal; each case requires a distinctive set of needs depending on its time and place. In addition, a distinction must be drawn between the learners' overall needs and the course needs (Dudley-Evans, \& St. John, 1998). Dudley-Evans and St. John synthesize the different available classifications and dichotomies of NAs into three main types: the Target Situation Analysis (TSA), the Learning Situation Analysis (LSA), and the Present Situation Analysis (PSA).To illustrate, "the TSA includes objective, perceived, and productoriented needs, the $\boldsymbol{L S A}$ includes the subjective, felt, and process-oriented needs, and PSA includes the strengths and weakness in language skills and learning experience" (p. 124). Accordingly, there will always be a need to apply regular needs assessments targeting the three different objectives.

Corpus studies have shown that there is a wide range of dissimilarities in academic discourse that are based on the different disciplinary environments and language groups. These differences underline the importance of "community, context and purpose in writing;" hence, "addressing students' target needs...helps clarify future directions for research" (Hyland, 2012, p. 44). Indeed, both multicultural, multilingual and multidisciplinary corpus and case studies confirm that academic discourse is not "a single monolithic entity" (p. 31), and a generalized model of writing will fail to take into account the multiplicity of genre and subgenres" 
(Casanave, 2002). Bocanegra-Valle (2016) emphasized the significance of attesting to what can be called "glocal needs" which blends the global needs shared by the international academic institutions and the local needs of the learner's particular EAP settings and courses. She stresses the significance of adopting a mixed methodology approach that combines quantitative data tools, such as questionnaires (which are highly popular), General English Proficiency (GEP) tests, and qualitative tools such as semi-structured interviews and non-participant observations. The methods for gathering the data for the NA vary according to the approach and the objectives of the analyst. Jordan (1997) listed fourteen different methods that include "documentation, tests, questionnaires, forms/checklists, interviews, recordkeeping, and observation" (p.30). Advanced documentation includes the educational background of the learners and any relevant aspects such as the socio-cultural background (depending on the objective of the NA). Needs assessment has proven to be a very effective pedagogical procedure that University of Auckland in New Zealand has implemented a mandatory Diagnostic English Language Needs Assessment (DELNA) program. The program is mandatory for all freshmen regardless of their language background, as it helps them choose later appropriate forms of academic language support (Read, 2008).

The first method of gathering information about the needs and the deficiencies of the learners is the previous research. Sources of information could be the published and unpublished literature, which includes studies based on teachers and applied linguists, learners, domain experts, and triangulated sources (Long, 2005). Long differentiated between triangulation by sources, that is when comparing the learners and instructors' views via one constant questionnaire, whereas triangulation by methods is when the learners and/or the instructors are studied via a questionnaire and interviews. Jordan (1997) suggested researching the language used in different modes and registers, and the situations where students face difficulties, while investigating a specific group of learners with a shared background. Language tests are classified into home tests, onentry tests, self-assessment, and class progress tests. They can be applied 
through formative and summative assessment tools, questionnaires, and/or error analysis. Observation and monitoring is another method that reveal the learners' difficulties and it is highly useful for perceiving the listening and speaking skills and for observing the learners' subjective needs and preferences. Surveying the background of the learners' language skills can easily be assessed through questionnaires that build up their profile. Structured interviews is a method that compensates the disadvantages of the questionnaires, as the interviewer will guarantee that all the questions are answered and will have the opportunity to follow up with further elaborations. Learner diaries, on the other hand, provide the analyst with a more subjective affective perspective of the learners' needs and the learning experience because they are based on introspection. Despite of the fact that it is time-consuming, to obtain more in-depth insights, the case-study approach is very illuminating, as well. Final evaluations and follow-up investigations often in the form of questionnaires allow for a solid assessment of the whole learning experience. Long (2005) added to this list more procedures: inductive and deductive. The inductive procedures are such as the use of expert intuitions; participant and non-participant observation; the learners' diaries and journals; role-play simulations; content, discourse and register analysis; and unstructured interviews. The deductive methods are such as the use of devices and instruments that include structured interviews, questionnaires, and criterion-referenced performance tests with pre-set categories (p. 31). In addition to specifying the objective of the NA, Long stressed the importance of choosing the right approach to the NA that corresponds to the syllabus content; in other words, the NA should be task-based if the course is task-based. Long (2005) lists 6 types of sampling: convenience sample where the participants are available and willing to participate, yet they may or may not be representative of the target population; a purposive sample where a group is chosen by the analyst as supposedly typical; a random sample where each member of the population had an equal chance of being selected; a Stratified random sample which is a random but proportionate sample within each sub-group or strata of the population of interest; a Cluster sample which is a random 
sample drown from the sub-groups for which the sampling frame can be determined; and a Systematic random sample which involves the selection of every $n t h$ person from the sampling frame.

Post-graduate students have different needs from the undergraduates, for their use of the language is more advanced and they are interested more in reading complex academic texts (Ostler, 1980). Postgraduate students in Ostler's study revealed their need to study specialized genre-based skills, such as reading academic journals, writing critiques and research proposals, and participating in panel discussions. The study has highlighted the importance of planning special classes to serve these needs and assessing the students' competence in these needed skills. Since it is important to consider the experts' perception as Long (2005) stressed, Shin (2008) surveyed the opinions of the postgraduate Korean teachers and their students studying engineering in London. The results of Shin's assessment has shown that the two groups of teachers and students agreed on integrating real-life communicative tasks relevant to the engineering community in the EAP syllabi. They also highlighted the importance of discipline-specific study and writing skills. Rostami and Zafarghandi (2014) study that investigated the needs of 90 chemistry students in Iran based on surveying their opinion in addition to 20 on their instructors. The findings of the study showed that both the teachers and the students perceived EAP as an important area of study. They also agreed that reading is the most prominent skill with special emphasis on vocabulary and reading speed as serving skills. In Egypt, El Deeb conducted a needs assessment study in 2007 to assess the needs of 100 postgraduate students of the Special Diploma in the Faculty of Education. The results of the study showed that EAP is "an effective approach for designing English language programs for postgraduate students" as it helped improving their language proficiency and deepening their academic achievement because the students showed preference to relate the language they study to their specializations. Moreover, the study highlighted the significance of using authentic texts and activities as they highly encouraged the students' positive involvement. Another study was conducted later on Arabic-speaking students by 
Alqahtani (2011) assessing the needs of postgraduate Saudi students studying at Southampton University in Britain. The study included 62 postgraduate students enrolled in the $\mathrm{MA}$ and $\mathrm{PhD}$ programs, in addition to 8 EAP teachers. The study revealed that there are specific needs related to the Saudi students studying in Britain, such as their academic and practical adjustment issues.

The present situation analysis study aims at understanding the needs of post-graduate students of humanities and social sciences in the Faculty of Arts (FoA), Cairo University under the credit hour system that was applied starting the academic year 2011-2012. The target population did not include any students from the English Dept., since they have already studied 5 English for Academic Purposes (EAP) courses in the undergraduate years, in addition to studying research and proposal writing in both the MA and $\mathrm{PhD}$ stages. Students from the other departments, however, study just a two-term general EFL course in their undergraduate years, and the initial observations showed that not all of their post-graduate programs include English-based courses such as EFL, ESP, EAP or specialized texts in English.

There are two research questions for this study. The first one is What are the requisite academic research skills for FoA scholars as perceived by their teachers? To answer this question, two interviews about the essential research writing skills that $\mathrm{PhD}$ students need were conducted with staff members from the English Dept. who have been teaching EAP to MA and PhD students in other departments. In addition, a questionnaire was filled in by 16 teachers of post-graduate programs in departments other than the English Dept. Parallel to the first question is the second question which is concerned with the students' perception: What are the FoAs postgraduate scholars' EAP perceived needs? To answer this question, interviews were conducted with 10 students (5 MA and $5 \mathrm{PhD}$ ), and questionnaires were filled in by 100 students with a randomly selected sample of MA and $\mathrm{PhD}$ students in the FoA who are not majoring in English Language and Literature. The following table illustrates the design of the study of the study. 
TABLE 1

RESEARCH QUESTIONS AND THEIR TOOLS

RESEARCH QUESTIONS
Tools

Tool

Validity
1 What are the requisite academic research skills for FoA scholars as perceived by their teachers?

2 What are the FoAs postgraduate scholars' EAP perceived needs?
a) Discovery interviews with teachers from the English Dept.
b) Questionnaires filled by teachers from other departments
a) Discovery interviews with students
b) Questionnaires filled by students

a) Reviewers

b) Reviewers, pilot questionnaire and Cronbach Alpha test

a) Reviewers

b) Reviewers, pilot questionnaire and Cronbach Alpha test

\section{Methodology}

To achieve triangulation by methods, the needs assessment surveyed the opinions of both the teachers and the students of the postgraduate programs in the FoA. Regarding the first research question, the teachers' data were collected via interviews and questionnaires. The first stage, that is the interviews, were semi-structured as the course of the interview depended on the interviewees' responses to the questions and the topics laid across. To check the validity of the interview's questions before conducting the interviews, the questions were given to two reviewers in the English Dept. to assess their clarity, relevance, and coverage. The reviewers confirmed that the questions were clear enough and that they serve the objectives of the interview.

The participants of the interviews who were two EAP teachers from the Department of English were chosen for three reasons; they both taught EAP to postgraduate students in other departments; they had received high 
quality training in teaching English as a second language; and they were available and willing to participate in the study. The first interviewed teacher (T1) is a lecturer who is a CELTA certified and has a 21-year experience in teaching EFL, ESP and EAP. He has taught EAP to $\mathrm{PhD}$ and MA students in the following departments: the Arabic Dept. (both linguistics and literature divisions), the Oriental Studies Dept., and the French Dept. The second interviewee (T2) is a lecturer who has the Royal Society of Arts Diploma and a 24-year experience in teaching linguistics, EFL, and ESP. She has taught the PhD students in the Arabic Dept, the literature division. The interviews took about 20-27 minutes in the staff room of the English Dept., and an interview protocol was used to guide the interview process. The interview questions comprised initially 15 items, the first four of which were about the teachers' expertise and background, while the rest were designed to cover the following topics:

1- Initial and final assessments of the students' needs.

2- Basic teaching goals

3- Differences among students from different departments or in the same department

4- The PhD EAP course description

The second stage in surveying the teachers' perception targeted the teachers of the subject courses who teach specialized courses in the departments of languages, humanities, and social sciences. They have the capacity to give insights of the specific realistic academic status quo, besides the aspired needs of their post graduate students regarding using English resources in their fields. Their judgment is based on their experience as teachers who have been teaching undergraduates, as practiced researchers in their fields who may have already published internationally, and as academic supervisors who have seen their students' mistakes. Therefore, it was decided that instead of an interview, a questionnaire should be used to survey as many views from different departments as possible. The participants consisted of 8 professors, 7 associate professors and a lecturer who have been teaching post graduate studies in their 
departments. They were chosen on the basis of their teaching experience, diversity of specialization and availability.

In addition to reviewing the literature of some relevant studies that assessed similar university students' needs in EAP courses (Qotbah, 1990; El Deeb 2007; Shin, 2008; Alqahtani, 2011; \& Rostami, \& Zafarghandi, 2014), the earlier discovery interviews with the EAP teachers helped in structuring the main objectives of the teachers' questionnaire. The questionnaire included both closed-form and open-form items. The closedform items are for the ease of record and analysis, as they assume that the strength of experience is linear and that attitudes can be measured. The open-form questions, on the other hand, helped in collecting the teachers' own specific information, opinions, and recommendations. The final version of the questionnaire included 13 items that were put under three main sections. The first section consisted of 8 items that were concerned with reviewing the present situation of the students. It addressed their general proficiency level in English and the quality of the academic English input they have in their undergraduate and post graduate courses. The second section addressed the students' specific EAP skills and was later replicated in the students' questionnaire to compare the teachers' opinions to the students' perspective. This part consisted of 5 items and was concerned with the students' four language skills-listening, speaking, reading, and writing: their importance to the students, the degree of their difficulty for the students, and the students' proficiency level of these skills. This section is concluded with two questions that asked the participants to rank the importance and difficulty of some sub-skills of writing. The part concerned with the writing skills was adapted from Qotbah's teachers' questionnaire (p. 370). This part was chosen because it included all the relevant aspects of academic writing skills which are writing short essays and reports, using writing techniques like planning and summarizing, writing English sources, Writing summaries or abstracts, writing assignments, expressing and defending stances, writing a literature review, writing the methodology of the study, using the correct terminology, organizing ideas in logical sequences, writing brief clear notes, organization of writing as a whole, explaining graphs, tables, charts and diagrams, and Writing correct 
grammar. Finally, the third section asked the participants about some demographic information and it included six items that comprised their background information. The demographic information part came at the end, as according to Dörnyei (2014), "the starter questions need to be interesting, relatively simple yet at the same time focused on some important and salient aspect, and certainly non-threatening/sensitive" (p. $61)$.

The questionnaire was written in English first then translated into Arabic to guarantee clarity of meaning and it was proofread by two colleagues from the Arabic Dept. (a lecturer and an assistant lecturer). A jury of two professors reviewed the questionnaire before piloting it on two colleagues to test feasibility, clarity of objectives, time taken, accuracy of the questions, appearance and layout, and any further suggestions. In addition, the reliability, validity, and internal consistency of the questionnaire were assessed using Cronbach Alpha by measuring the stability of the variables. The results showed a high degree of reliability (0.831) and validity (0.911), which is a good indication of the internal consistency of the questionnaire. The total number of the respondents was 16 teachers, and descriptive statistics were used to measure the frequencies and percentages of the teachers' answers.

Concerning the second research question, in order to understand the needs of the postgraduate students as perceived by themselves and to design a questionnaire that can give a preview of the present situation, I conducted a number of semi-structured discovery interviews with ten $\mathrm{MA}$ and $\mathrm{PhD}$ students. The interview protocol included 16 guiding questions. Ten questions tackled the students' perception of their English language skills, and six questions where about their English-based courses that they studied in their MA and $\mathrm{PhD}$ programs. Further questions were developed and adapted throughout the interview to help the interviewees open up and express themselves in their own terms at their own speed. These semistructured interviews generated a variety of qualitative data as the interviewed participants belonged to different departments in the FoA, and hence have different perspectives on the topic. The sample included students from the following departments: The Arabic Dept. (1 MA student and 1 
$\mathrm{PhD}$ student), The Classical Studies Dept. (1 MA student and $1 \mathrm{PhD}$ student), The Japanese Dept. (1 PhD student), The History Dept. (2 PhD students), The Geography Dept. (1 PhD student), The Psychology Dept. (1 MA student), and The Libraries and Documents Dept. (1 MA student and 1 $\mathrm{PhD}$ student) - a total of $4 \mathrm{MA}$ students and $6 \mathrm{PhD}$ students.

The participants' responses from the two discovery interviews with the teachers and the students were analyzed thoroughly. All expectations, suggestions and recommendations that were mentioned in these interviews were noted and presented in the questionnaire given to a larger scale of MA and $\mathrm{PhD}$ students. As mentioned earlier, the students' questionnaires mirrored the teachers' in its form and content (Check the appendix for the joint questions). Like the one presented to the teachers, the students' questionnaire was written in English first then translated into Arabic to guarantee clarity of meaning and it was proofread by the same reviewers of the teachers' questionnaires. A jury of four professors from the Faculty of Higher Education, and the Faculty of Arts reviewed the questionnaire before piloting it. All their comments were taken into consideration and some changes were applied to the form and content of the questionnaire. Just as with the subject teachers' questionnaire, the reliability, validity, and internal consistency of the questionnaire were tested using Cronbach Alpha. The results showed a high degree of reliability $(0.759)$ and validity $(0.871)$, which is a good indication of the internal consistency of the questionnaire. The questionnaire was piloted on a group of 10 students (5 MA and $5 \mathrm{PhD}$ ) from departments other than the English Department. Based on this pilot, some items were re-written and one yielded unimportant, and, therefore, deleted. Finally, in response to the suggestions of the pilot questionnaire participants, it was decided for the administration of the questionnaire to be both online and in paper form for the ease of distribution and, later, analysis. The number of participants who filled in the questionnaire was $100(65 \mathrm{PhD}$ and $35 \mathrm{MA}$ )and they belonged to almost all the departments in the FoA. Descriptive statistics were used to measure the frequencies and percentages of the students' answers. Finally, an independent t-tests was run to test the differences between the teachers and the students. 


\section{Results}

\section{The EAP Teachers' Questionnaire}

The two EAP teachers interviewed shared a substantial experience in teaching; they have been teaching for over twenty years and they have had international teaching training. They were asked by the departments they taught in to develop their ILOs. Furthermore, due to the heterogeneity of the students' proficiency level in the same class, both teachers set their priority to improving the students' grammatical skills. Both of them included in their courses the following tasks: using writing techniques like planning and summarizing, writing summaries, and organizing ideas in logical sequences.

While both teachers focused on the writing skill, T1 focused on the main features of essay writing, while $\mathrm{T} 2$ took a genre-based approach and focused on these features in published papers she brought to class. T2 did not find it important to give the students any proficiency test at the beginning of the course, as she expected that they are all in the same level-which turned out to be a false assumption. During the interview, it was clear that the specialization and experience of the two teachers determined the course objectives and affected the material selection. Nevertheless, these ILOs were still not officially documented or implemented in these programs; accordingly, in the following years of teaching these programs, every teacher had to come up with their own ILOs and teaching material. Table 1 summarizes the two experiences.

Table 2

Comparing the Responses of the Two Exploratory Teachers' Interviews

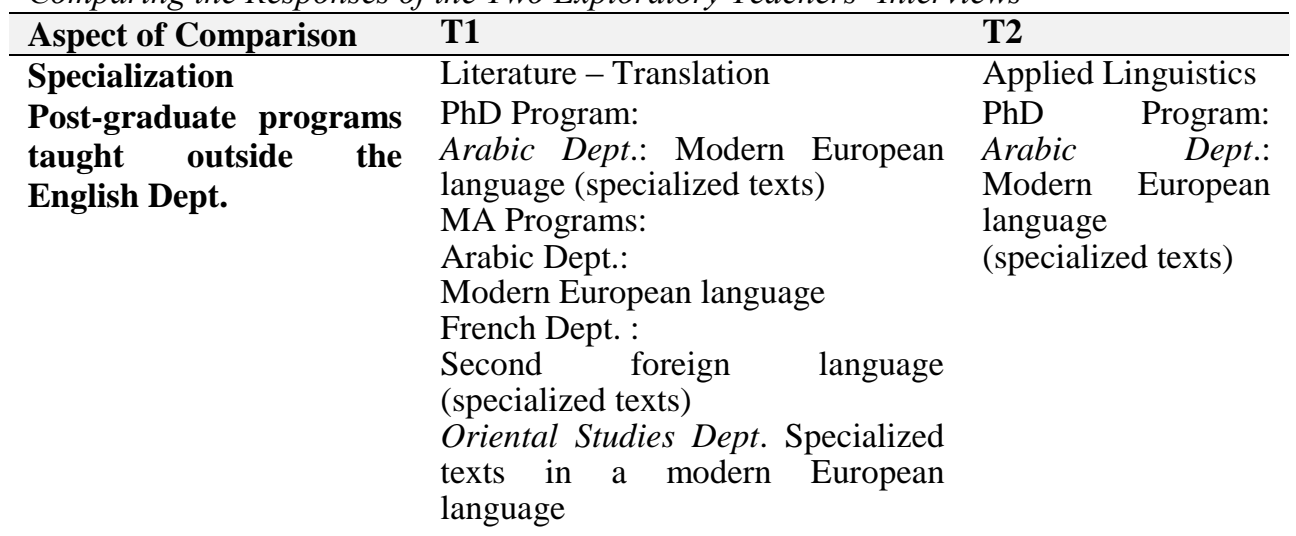


Needs Assessment before Yes - Proofreading and editing test No the course

Main objective

Materials used

Skills covered

Focus of the writing skill

Method used

Students'

level

Activities

assignments

proficiency

and Project, presentation, and a paper

\section{Cooperation with other teachers}

Tasks included in the course
Learner-center negotiated

Intermediate they present at the end

To be able to write an essay using the main features of EAP writing academic sentence structure

To be able to understand the structure and characteristics of the IELTS

Cambridge Academic Writing book

Listening, Reading, and Writing

Analyzing and writing essays

No

Writing short essays

Using writing techniques like planning and summarizing

Citing English sources:

Writing summaries or abstracts

Writing assignments

Using the correct terminology

Organizing ideas in logical

sequences

Organization of writing as a whole
To be able to write correct
To be able to analyze, evaluate and edit abstracts of published research papers

To be able to use correct tense and sentence structure for the different sections of the research paper

*Power Reading

*English for

Academic Research:

Writing Exercises

Reading and

Writing

Analyzing and editing abstract writing

Task-based

Intermediate

Grammar exercises, midterm exam and re-writing their MA abstract

No

Using writing techniques like planning and summarizing

Writing summaries or abstracts

Organizing ideas in logical sequences 


\section{The Subject Teachers' Questionnaires}

Although the demographic information of the respondents came at the end of the questionnaire, it is presented here at the beginning to give a vivid description of the background of the respondents. Eight participants were assistant professors, while seven were professors and only one participant was a lecturer. They belonged to the departments of Arabic, Sociology, Psychology, Libraries, documentation and information technology, History, Philosophy, Oriental Studies and Geography, and they all spoke English as their first foreign language.

The first section of the given questionnaire aimed at understanding generally the students' current language skills and their use from their subject teachers' perspective. In this section, $93.8 \%$ of the teachers who filled in the questionnaire believed that the undergraduate English courses that their students take in their departments are not sufficient for developing their English language proficiency. The following reasons were given:

1- The courses they are taught are not sophisticated enough.

2- The number of hours is not sufficient for them to learn specialized English terminology and grammar.

3- There are no grades allocated for the course work of these courses.

4- The texts used mostly are literary and there is not enough time spent on teaching the technicalities of writing.

5- Students do not study enough specialized texts in their fields.

6- The courses do not improve the four language skills of the students

7- The courses do not qualify them for the post graduate studies.

Regarding academic English in particular, all of the participants agreed that their students need to get exposed more to English as used in research writing for the following reasons:

1- It familiarizes them with specialized academic texts in its source language and not translated.

2- A post-graduate student must be proficient in speaking and writing 
English.

3- It enables them to translate academic texts in English themselves and not rely on unreliable translations.

4- Students need to know how to write abstracts for conferences and publications.

5- They do not read much in English, whether specialized or nonspecialized texts.

Answering the item about the general proficiency level of their postgraduate students, $50.0 \%$ believed it is Intermediate (B1), 31.3\% estimated it as Elementary (A2), and $12.5 \%$ assessed it as Beginner (A1), and one teacher expressed that it varied from one student to another. When asked about their postgraduate students' present command of English language, $43.8 \%$ found it unsatisfactory, $18.8 \%$ unsatisfactory at all, $18.8 \%$, satisfactory, and $18.8 \%$ satisfactory to an extent. Hence, the results show that more than half the teachers were not satisfied with their students' command of the language (the unsatisfied combined with the unsatisfied at all $=62.3 \%)$.

The second part of the questionnaire focused on understanding the students' current academic English skills. The following part of the questionnaire asked the teachers to estimate the degree of importance (item 9), difficulty (item 10) and mastery (item 11) of the four language skills. Regarding the importance of the four language skills, the general trend indicated that it was towards the (Important) choice, with mean (4.32), and standard division (0.61). The respondents believed that the most important skills were Writing, Reading, and Listening, with arithmetic mean (4.75), (4.62), and (4.13) respectively, while the least important skill was Speaking, with arithmetic mean (3.81). When asked about ranking the four language skills in terms of difficulty, the general trend of the study sample indicated that it is towards (Difficult), with arithmetic mean of(2.0), and standard division (0.52). The most difficult skills were Speaking and Listening, with arithmetic mean of (1.63) and (1.69), respectively. In contrast, the least difficult skills according to the respondents were Reading and Writing with 
arithmetic mean of (2.62) and (2.06). Lastly, the respondents described their students' mastery of the language as generally (Good) with mean of (2.07) and standard division (0.75). The skills whose mastery was perceived as good were Reading and Listening with arithmetic mean of (2.94) and (1.88), respectively, while the skills whose mastery was perceived as least good were Writing and Speaking, with arithmetic mean of (1.76) and (1.75).

The last section in the questionnaire was concerned with the subskills of the academic writing skill. The results of the teachers' estimation of the degree of importance showed that the most important writing skills were Citing English sources, Using the correct terminology, Writing summaries or abstracts, Writing a literature review, and Writing correct grammar, with arithmetic mean of (3.94), (3.88), (3.81), (3.72), and (3.69) respectively. On the other hand, the least important writing skills were writing assignments, expressing and defending stances, and explaining graphs, tables, charts and diagrams, with arithmetic mean of (3.25), (3.06), and (3.00) respectively.

The teachers' estimation of their students' command of these subskills showed that the general trend of the study sample indicated that it was towards the (Good), with mean of (1.75), and standard division (0.62). In response to this question, the teachers expressed that their students were good in the following writing skills respectively: Using the correct terminology, Citing English sources, Using writing techniques like planning and summarizing, Writing short essays and reports, and Writing correct grammar, with arithmetic mean of (2.38), (2.31), (2.10), (2.00), and (1.75). The skills where they found their students least good were Writing brief clear notes and Writing assignments, with arithmetic mean of (1.44), and (1.38).

\section{The Students 'Interviews}

Concerning their language learning background, the participants have revealed that they came from diverse backgrounds. However, almost all of them agreed that they needed extra-curricular English courses after graduation to improve their proficiency level. Their focus was not on EAP, 
but rather on general and conversational English. The reason is that their language use is confined to reading academic sources and presenting in international conferences. Four of the six $\mathrm{PhD}$ students revealed that their only academic writing in English attempt was when they had to write the summary and abstract of their MA thesis. They revealed that it was not an easy task and that they had to ask for help from a friend or a colleague in the English Dept. to proofread or translate the abstract and the summary. Two $\mathrm{PhD}$ students said that in addition to writing the abstract and summary of their thesis, they had to write grant proposals for international funding organizations which are The Binational Fulbright Commission in Egypt, and the DAAD: German Academic Exchange Service. With regard to the MA students, they did not have any experience of writing in academic English except for one participant who translated a conference abstract into English. Regarding academic readings, the $\mathrm{PhD}$ students expressed that they did not have to read academic texts in their specialization in English during their required courses, whether in the MA or the PhD programs. Nevertheless, their supervisors did recommend English sources for them to read and use in their theses and dissertations. Not surprisingly, the younger MA students confirmed the $\mathrm{PhD}$ students' claim and expressed the difficulties of comprehending academic sources in English on their own.

Another challenge that both groups agreed on facing was the fact that academic writing in English is more difficult than in Arabic or in their language of specialization. They believed the difficulty was in terms of the technical terminology and the style of academic English in general. They looked at it as a more advanced level of English than the level with which they were familiar. In addition, they believed that it is easier to focus on improving their reading and speaking skills, as it needs more effort and time to improve their writing skills, than to work on their speaking and reading skills.

When asked about their fluency of academic versus general English, there was a consensus that they are more fluent in general than academic and in reading than writing. The justification was that they can easily and independently use the help of a dictionary to understand the texts, but with 
writing, it is more sophisticated as they find it difficult to express their ideas or other people's ideas. Hence, although they found writing a more important skill than reading, as it enables them to publish internationally, they admitted finding it more difficult. One participant explained that she believes that writing is an umbrella skill and that by mastering one can master the other three skills. Regarding ways of improving their academic writing skills, the participants did not have a specific plan to do that. They just agreed on the importance of reading academic texts in order to improve academic writing.

The second part of the interview aimed at understanding the features of the EAP courses they studied during their MA and $\mathrm{PhD}$ programs. According to the participants, not all programs included English courses, and those which had English courses, had different objectives. These objectives focused on translation, literary analysis, and comprehension skills. Regarding the content of the course, they either found it irrelevant to their current academic interests, or too simple for their academic level.

\section{The Students 'Questionnaires}

Regarding the students' current language skills and their use, the first item in the questionnaire gave the respondents the freedom to choose more than one purpose for using English language. 85\% of the answers indicated that they use English for reading research, while almost half the answers indicated that they use it for writing (44\%).In addition, the results have shown that $67 \%$ of the respondents had taken an international TOEFL test before, although the local/institutionalized one is the one required by the FoA as a pre-requisite before defending any thesis or dissertation. When asked about the reason why they took the test, the answers were:

1- a pre-requisite for defending my MA thesis or $\mathrm{PhD}$ dissertation,

2- to apply for a scholarship, and

3- to know my exact proficiency level, and, therefore, improve it.

About $59 \%$ of the respondents said that they took courses in English in the last 5 years. When asked about the nature of the courses, they said 
they included English phonetics, English conversation, General English, EAP (as part of a Faculty grant), and online courses.

Regarding the importance of the four skills from the students' perspectives, the general trend of the study sample indicated that it was towards "Very important", with mean (4.63), and standard division (0.45). In the order of the most important skills came Reading, Listening, and Speaking, with arithmetic mean of (4.68), (4.65), and (4.64), respectively. Unexpectedly, the least important skills was Writing, with arithmetic mean of (4.59). As for the level of difficulty, the general trend of the study sample indicated that it is towards "Mildly difficult", with mean of (3.14), and standard division (0.80). The most difficult were Reading and Speaking, with arithmetic mean of (3.70) and (3.03), respectively. The least difficult ones were Writing and Listening, with arithmetic mean of (3.01) and (2.85). Finally, when asked about their mastery of the four skills, the general trend of the study sample was towards "Good", with mean of (2.25), and standard division (0.72). According to the results the order of the skills in terms of their mastery was Reading and Listening, with arithmetic mean of (2.64) and (2.26), respectively, and writing came at the end of the four skills with mean of (2.06).Regarding items number 10 and 11, 45\% said that they have studied English for academic purposes before, while $21 \%$ only indicated that they have studied English for research before.

The results of the importance of the sub-writing skills demonstrates that the general trend of the answers were towards Important, with mean of (3.33) and standard division (0.53). The most Important writing skills were Using the 1-correct terminology, 2- Citing English sources,3- Writing correct grammar, and 4- Writing summaries or abstracts. On the other hand, the least Important skills were Expressing and defending stances, writing assignments, and Explaining graphs, tables, charts, and diagrams), with arithmetic mean (3.18), (3.14), and (2.92).

Concerning how proficient they believe they are with reference to these writing skills, the general trend of the responses was toward Good, with mean of (1.84) and standard division (0.61). The skills were most of 
the students found themselves good at were 1-Citing English sources, 2Using the correct terminology, 3-Writing correct grammar, 4- Writing brief clear notes, with arithmetic mean of (2.28), (2.13), (2.03) and (1.93), respectively. In contrast, the skills where they found themselves least good Expressing and defending stances, writing a literature review, and Explaining graphs, tables, charts, and diagrams, with arithmetic mean of (1.69), (1.64), and (1.53).

On comparing the responses of the students to those of the teachers, the results show that the differences were significant only in the items related to the importance and the difficulty of the language skill, with pvalue less than 0.05 . Regarding the importance of the language skills, according to the teachers, the most important skills were Writing then Reading, while for the students, they were Reading then listening. As for the most difficult skills, for the teachers they were Speaking then Listening, while for the students they were Reading and Speaking .

\section{Discussion}

The two interviews with the EAP teachers have revealed the following challenges:

1- There is a discrepancy in the English language proficiency levels of the students as they come from different educational backgrounds.

2- It is difficult with the insufficient number of English courses in the undergraduate levels to focus on improving the postgraduates' general English skills and EAP skills at the same time in just one course.

The interviews showed the lack of uniformity in the students' proficiency level; their levels varied from pre-intermediate to advanced due to their different educational background; for instance, some of them are not Egyptians, which means that they have experienced a totally different educational system that might have neglected at all teaching English as a foreign language (as in the case with the Syrian educational system). As a result, the postgraduate program designer needs to make a placement test, so that the students with a lower proficiency level would be placed in one group, and those with a higher proficiency level would be placed in another. 
Another solution to the disparity in the students' level is to design a course that addresses this disparity. A taxonomy with progressive levels of competence will accommodate these different levels seamlessly. Thus, SOLO taxonomy can be useful in this case more than Bloom's for the following reasons:

1- SOLO taxonomy describes and introduces the subject content from simple to complex which will stimulate the students with lower proficiency levels and at the same time attend later to the needs of the students with higher proficiency levels.

2- SOLO taxonomy can be easily explained to the students at the beginning of the course, and they can track their progress from the surface to the deep levels through the color coding and the icons used in each section.

The questionnaires have shown a considerable consensus among the subject teachers that the English courses their students study in the undergraduate level are insufficient. The reasons are related to the teachers' experience, the course design, and the textbook or the materials used; there seem to be a deficiency of consistency in these three aspects. The teachers' specializations and experience usually have an impact on the course objectives and materials; for instance, if the teacher is specialized in literature, they would focus mainly on teaching short stories, while if they are specialized in linguistics, they would focus mainly on language skills. In addition, most of the time the materials taught are either irrelevant to the students' specialization, due to lack of communication with the students' departments, or proficiency level, due to lack of placement tests. Moreover, since different teachers teach each year in those departments, there are no consistency in the teaching policy, which may lead to the repetition of the same goals and materials in the second year. As for the post graduate programs, it was recommended that English becomes an obligatory course and not an elective one, to ensure that all the students are familiarized with specialized academic English. In fact, the questionnaire has also shown that the subject teachers are not necessarily aware of what is being taught in the 
English courses in the under- or post-graduate programs; they are aware of their insufficiency or ineffectiveness. Hence, it is important to open a channel with the subject teachers before designing EAP courses.

Regarding the four skills, although there is an agreement on the importance of the written skills, i.e. Reading and Writing over the spoken ones, i.e. Listening and Speaking, it was acknowledged that Writing in particular is the most important, although students do not master it despite the fact that according to the respondents it should not be very difficult for them. To sum up, the following are recommendations based on the teachers' input:

1- Increase the number of hours of teaching both general and specialized English.

2- Assign grades for the course work of these courses.

3- Incorporate the four skills, and not just focusing on reading and writing despite their importance in the under-graduate stage.

4- Give students placement tests to address their actual proficiency levels.

5- Amend the post-graduate bylaws so to make EAP an obligatory course and not an elective one.

6- Train students on academic writing for publishing, and not just for reading or translation.

7- Design a course with objectives that start from simple to complex to accommodate all levels of students.

The results of the students' interviews have revealed that the academic goals of the MA students are different from the $\mathrm{PhD}$ students when it comes to EAP. While the MA students were interested in improving their reading skills, the $\mathrm{PhD}$ students were keener to enhance their writing skills. The reason for that was that MA students are in the beginning of their graduate academic career. They have not read much yet about their specialization, neither in English nor in Arabic. They actually are in the exploration stage where they learn what resources to read, how to get them and how to read them critically. On the other hand, the PhD students have already learnt that either through guidance or through first-hand experience. Their focus in this stage is rather on publishing, locally and internationally, 
since they have to publish two publications locally or one internationally before they got to defend their dissertations. In conclusion, the following recommendations were implied from the participants answers in the interviews:

1- Increase the number of English language courses in the undergraduate years.

2- Give these courses to small groups of learners who share the same proficiency level.

3- Teach research writing in English, and not just general English, and it can be an elective course beside a compulsory EAP course.

4- Have compulsory academic writing courses in the MA and $\mathrm{PhD}$ programs, instead of having to take TOEFL as an indication of their language proficiency.

The questionnaires, on the other hand, have revealed different insights. The have shown that the primary reason for studying English was for reading and not writing research. The reason could be that if the participants are already specialized in another foreign language, they will not need the English language to publish internationally. Also, as indicated by the exploratory interviews, reading is a priority for the MA students, and for the $\mathrm{PhD}$ students it is an easier skill than writing. Regarding taking placement or admission tests in English, the results were actually astonishing as although taking a TOEFL test is a pre-requisite for both the MA and PhD degrees, only $29 \%$ said that they do not intend to take any in the future, which indicates a lack of knowledge of the bylaws of the FoA, and a lack of interest in the language itself. Finally, with reference to the type of courses the participants said that they took in the last 5 years, it seems that there is also lack of awareness of the objectives of these courses and the needs of the students themselves. They focus on either general English only to know their proficiency level or to apply for a scholarship, and on conversational English only to improve their speaking skills which should help them if they want to present in an international conference. Accordingly, a clear taxonomy of the language skills and how they can use 
it should help them in setting their priorities, and in having a language plan that will be affective and relevant to their needs.

Finally, the responses regarding the skills were unforeseen. The results have shown that Reading is perceived to be the most important skill and the most difficult at the same time, while Writing was perceived to be the least important skill and the least difficult. The interpretation of this result is that the participants of the questionnaires perceive Reading as a gatekeeper to the academic world in English. Moreover, perceiving Writing as easier than Reading shows that they are not experienced enough in academic writing in English. They do not know what they actually miss, since only $20 \%$ of them have studied academic English, and with such few number of hours dedicated to the EAP courses, they must have not practiced enough writing.

\section{Conclusion}

This study was concerned with portraying a profile of needs for the post-graduate students in the FoA, Cairo University. The interviews and questionnaires with the teachers and students have shown that both groups of participants believe that there is a need to increase general English and EAP courses. EAP teachers and specialized subject teacher expressed their disappointment at the students' proficiency level and the fact that there is no clear pedagogical plan for teaching English. They recommended many changes with regard the bylaws that should allow for more credited courses in both the under-graduate and the post-graduate levels.

According to the needs assessment study, it is suggested that students can work on and improve the four skills on a long-term plan, where there is a focus first on general English in the four undergraduate years. It is significant to ensure that all the graduates are in the upper intermediate level by the time they graduate. Although they might be resistant at the beginning to study this foreign language seriously beside their language of specialization, they will appreciate it as it will be a true addition to their linguistic skills. Moreover, based on the interviews and the questionnaires, I suggest giving extra focus to the spoken skills: Listening and Speaking at the beginning because students are always motivated to speak the language 
and to be able to carry on a conversation with a native speaker. In addition, in the post-graduate years, attending international conferences (whether abroad or in Egypt) is important for enhancing the researchers' academic career, and being confident about one's foreign language ensures valuable participation and interaction. Consequently, comes the focus on Reading and Writing simultaneously, since the students who filled in the questionnaire found Reading is the most important-which is consistent with Ostler's (1980), and Rostami and Zafarghandi's (2014) findings-while their teachers insisted it is Writing. Teaching English for general purposes intensively (4 courses in the BA) paves the way to teaching EAP in the postgraduate level. During the MA and PhD program, a GB approached should be very effective. Students will then be familiarized with a variety of academic genres. They will get to read and write about more specialized topics.

Hence, an EAP course designed for the postgraduates should include academic texts relevant to the specializations of the students. It should address all the four skills as much as possible through oral discussions and shown videos. The course's main writing objectives includes the skills which both groups of teachers and students found important, which are: citing English sources, writing summaries or abstracts, and writing correct grammar. As for teaching specialized part-genres like writing a literature review in English, it must be done by the specialized teacher as an advanced step after teaching basic general and specific academic writing skills. As a matter of fact, in this needs study, the students' specialization was not a variable, as it was difficult to assess the needs of the different departments separately. Moreover, it did not compare the students opinions before and after studying EAP courses. It is, thus, recommended that further studies investigate of students studying the same program and compare these needs before and after studying the EAP courses. 


\section{References}

Alqahtani, M. (2011). An investigation into the language needs of Saudi students studying in British postgraduate programmes and the cultural differences impacting on them (Doctoral dissertation). Retrieve from https://eprints.soton.ac.uk/198175/

Altschuld, J. W., \& Eastmond, J. N. (2010). Needs assessment: Getting started. Los Angeles: Sage.

Bocanegra-Valle, A. (2016). Needs analysis for curriculum design. In K. Hyland, \& Ph. Shaw (Eds.), The Routledge handbook for English for academic purposes. New York: Routledge.

Casanave, C. P. (2002). Writing games: Multicultural case studies of academic literacy practices in higher education. Mahwah N.J: L. Erlbaum.

Dudley-Evans, T., \& St John, M.J. (1998). Developments in English for specific purposes: A multi-disciplinary approach. Cambridge: Cambridge University Press.

El Deeb, E. M. E. S. (2007). The effectiveness of an English for academic purposes programme on developing the required study skills of postgraduate students at the Faculty of Education, Helwan University. Unpublished doctoral dissertation. Helwan University, Cairo, Egypt.

Hyland, K. (2012). Corpora and academic discourse. In K. Hyland, Ch. M. Haut, \& M. Hanford (Eds.), Corpus applications in applied linguistics. London: Continuum International Publishing Group.

Jordan, R. R. (1997). English for academic purposes: A guide and resource book for teachers. Cambridge: Cambridge University Press. https://doi.org/10.1017/CBO9780511733062

Long, M. H. (2005). Second language needs analysis. Cambridge, UK: Cambridge University Press.

https://doi.org/10.1017/CBO9780511667299 
Ostler, S. E. (December 01, 1980). A Survey of Academic Needs for Advanced ESL. Tesol Quarterly, 14, 4, 489-502.

Qotbah, M. A. (1990). Needs analysis and the design of courses in English for academic purposes: A study of the use of English language at the University of Qatar (Doctoral dissertation). Retrieved from http://etheses.dur.ac.uk/1505/

Read, J. (January 01, 2008). Identifying academic language needs through diagnostic assessment. Journal of English for Academic Purposes, 7, 3, 180-190.

Rostami, F., \& Zafarghandi, A. M. (2014, July). EAP needs analysis in Iran: The case of university students in Chemistry Department. Journal of Language Teaching and Research, 5(4), 924-934.

Sabrina, H. (2013). An EAP syllabus for first year economics students the case of the faculty of economics, business and management sciences (Master's thesis). Retrieved from https://www.univsetif2.dz/images/PDF/magister/MLA23.pdf

Shin, I. (January 01, 2008). Necessary skills in English for Korean postgraduate engineering students in London. Educate Special London issue,, 8(2), 50-61. 


\section{Appendix: Common questions in the subject teacher and the students' questionnaires}

9- How do you believe the following skills are important for your students? Please put a tick against each one as applicable to you:

\begin{tabular}{|l|l|l|l|l|l|}
\hline Skills & $\begin{array}{l}\text { Very } \\
\text { important }\end{array}$ & Important & $\begin{array}{l}\text { Important } \\
\text { to an } \\
\text { extent }\end{array}$ & Unimportant & $\begin{array}{l}\text { Unimportant } \\
\text { at all }\end{array}$ \\
\hline Listening & & & & & \\
\hline Speaking & & & & & \\
\hline Reading & & & & & \\
\hline Writing & & & & & \\
\hline
\end{tabular}

10- How do you believe the following skills are difficult for your students? Please put a tick against each one as applicable to you:

\begin{tabular}{|l|l|l|l|l|l|}
\hline Skills & $\begin{array}{l}\text { Most } \\
\text { difficult }\end{array}$ & difficult & $\begin{array}{l}\text { Mildly } \\
\text { difficult }\end{array}$ & $\begin{array}{l}\text { Less } \\
\text { difficult }\end{array}$ & $\begin{array}{l}\text { Least } \\
\text { difficult }\end{array}$ \\
\hline Listening & & & & & \\
\hline Speaking & & & & & \\
\hline Reading & & & & & \\
\hline Writing & & & & & \\
\hline
\end{tabular}

11- Please indicate your students' mastery level in English as per the following table for each of the four skills: listening, speaking, reading and writing.

Choose only one description for every skill. For example: Listening = poor

\begin{tabular}{|c|l|l|l|l|}
\hline Skill & $\begin{array}{c}\text { Weak } \\
\text { (They can } \\
\text { barely } \\
\text { understand } \\
\text { or use it for } \\
\text { general } \\
\text { purposes) }\end{array}$ & $\begin{array}{c}\text { Good } \\
\text { (They can } \\
\text { understand and } \\
\text { express myself) }\end{array}$ & $\begin{array}{c}\text { Very Good } \\
\text { (They can } \\
\text { understand } \\
\text { and produce } \\
\text { general } \\
\text { content) }\end{array}$ & $\begin{array}{c}\text { Excellent } \\
\text { (They can easily } \\
\text { understand and } \\
\text { produce general } \\
\text { and academic } \\
\text { English) }\end{array}$ \\
\hline Listening & $\square$ & $\square$ & $\square$ & $\square$ \\
\hline Speaking & $\square$ & $\square$ & $\square$ & $\square$ \\
\hline Reading & $\square$ & $\square$ & $\square$ & $\square$ \\
\hline Writing & $\square$ & $\square$ & $\square$ & $\square$ \\
\hline
\end{tabular}


12-Use the following scale to estimate the degree of significance of the following writing skills and 13-your students' degree of present command of the skill in English:

\begin{tabular}{|c|c|c|c|c|c|c|c|c|}
\hline \multirow[b]{2}{*}{ Writing Skill } & \multicolumn{4}{|c|}{ 12- Degree of Importanc } & \multicolumn{4}{|c|}{ 13- Degree of Proficiency } \\
\hline & 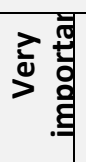 & 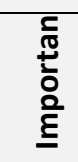 & 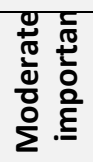 & 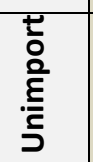 &  & 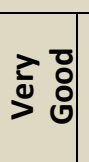 & $\begin{array}{l}\text { ¿ } \\
\text { : } \\
\end{array}$ & ర్లా \\
\hline $\begin{array}{l}\text { a. Writing short } \\
\text { essays and reports }\end{array}$ & & & & & & & & \\
\hline $\begin{array}{lr}\text { b. Using } & \text { writing } \\
\text { techniques } & \text { like } \\
\text { planning } & \text { and } \\
\text { summarizing } & \end{array}$ & & & & & & & & \\
\hline $\begin{array}{l}\text { c. Citing English } \\
\text { sources }\end{array}$ & & & & & & & & \\
\hline $\begin{array}{l}\begin{array}{l}\text { d. Writing } \\
\text { summaries } \\
\text { abstracts }\end{array} \\
\end{array}$ & & & & & & & & \\
\hline $\begin{array}{l}\text { e. Writing } \\
\text { assignments }\end{array}$ & & & & & & & & \\
\hline $\begin{array}{l}\text { f. Expressing and } \\
\text { defending stances }\end{array}$ & & & & & & & & \\
\hline $\begin{array}{l}\text { g. Writing } \\
\text { literature review }\end{array}$ & & & & & & & & \\
\hline $\begin{array}{ll}\text { h. Writing } & \text { the } \\
\text { methodology } & \text { of } \\
\text { the study } & \end{array}$ & & & & & & & & \\
\hline $\begin{array}{ll}\text { i. Using } & \text { the } \\
\text { correct } & \\
\text { terminology } & \\
\end{array}$ & & & & & & & & \\
\hline $\begin{array}{ll}\text { j. Organizing ideas } \\
\text { in } & \text { logical } \\
\text { sequences } & \\
\end{array}$ & & & & & & & & \\
\hline $\begin{array}{ll}\begin{array}{l}\text { k. Writing } \\
\text { clear notes }\end{array} & \text { brief } \\
\text { clear }\end{array}$ & & & & & & & & \\
\hline $\begin{array}{l}\text { I. Organization of } \\
\text { writing as a whole }\end{array}$ & & & & & & & & \\
\hline $\begin{array}{ll}\text { m. Explaining } & \\
\text { graphs, } & \text { tables, } \\
\text { charts } & \text { and } \\
\text { diagrams } & \end{array}$ & & & & & & & & \\
\hline $\begin{array}{l}\text { n. Writing correct } \\
\text { grammar }\end{array}$ & & & & & & & & \\
\hline
\end{tabular}

Other Skills: 